\title{
DEMAND SHIFTING, OPTIMAL FIRM GROWTH, AND RULE-OF-THUMB DECISION MAKING
}

\section{Henry G. Grabowski}

I. The basic model, 217. - II. Multiplicative demand curves and steady growth expectations, 222. - III. Equilibrium solutions, 226. - IV. Nonconstant returns to scale, 230. - V. Rule-of-thumb decision making and steady growth solutions, 232. - VI. Summary and conclusions, 234.

It is well known that firms in oligopolistic market structures prefer to compete by demand-shifting strategies like new product development, advertising, and the like, rather than trying to influence demand directly by price. The reasons that firms avoid price competition in this situation are captured neatly in the competitive response patterns of the "kinked" demand curve model. On the other hand, outlays for product development and advertising have the character of investment decisions in that they produce a stock of assets, often intangible, which are less vulnerable to immediate imitation by rivals. Moreover, since these outlays directly influence the real and perceived quality of a firm's products, they can serve as a powerful means for its rapid advancement forward or backward in an oligopolistic setting. Therefore, rival demand-shifting outlays will usually be a central mode of competition in such market structures.

In this paper, demand-shifting behavior will be analyzed using a capital-theoretic model with oligopolistic interdependence. A model of the advertising decision under monopolistic conditions analyzed previously by M. Nerlove and K. J. Arrow has been adapted for this purpose to a duopolistic market situation. ${ }^{1}$ The present inquiry will focus on equilibrium steady growth solutions and will consider in particular how a firm's growth in demand-shifting activity is affected by different factors, including various parameters relating to its rival's situation. The equilibrium steady-growth paths analyzed here will be shown to be solutions for a Cournot type model as well as for a rule-of-thumb decision-making approach commonly alluded to in the business trade literature. Most of the formal results obtained for the duopoly situation can be extended directly to the more general oligopoly model.

\section{The Basic Model}

The basic assumption of the model is that each oligopolistic firm may shift its own demand curve as well as that of its rivals by

1. M. Nerlove and K. J. Arrow, "Optimal Advertising Policy Under Dynamic Conditions," Economica, XXXIX (May 1962), 129-42. 
investment in activities like research and development and advertising. As indicated above, instead of dealing with multiple interactions of the general oligopolistic situation, we shall consider only the duopoly case in the formal analysis. Furthermore, the two duopolistic firms are assumed not to compete with each other by price changes, but instead devote all their managerial energies to demandshifting strategies. This aspect of the model is in accordance with prevalent studies of competition in oligopolistic industries. ${ }^{2}$

For the purposes of analytical simplicity, we shall also assume that there is only one type of demand-shifting activity undertaken by each firm. ${ }^{3}$ Investment in this activity will augment the stock of real capital assets for the firm in some fashion, which in turn will affect its demand curve positively and that of its rival adversely. ${ }^{4}$ At any moment, the firm's stock of such assets is directly measured by the cumulative amount of dollars invested in the past minus any losses due to natural depreciation and obsolescence of these assets.

What assumptions are reasonable regarding the technology of demand shifting under rivalry? First, we know that in actual practice demand-shifting activities like $R \& D$ and advertising do not instantaneously affect demand, but are subject to various technological and distributional lags. In some cases these lags are relatively unimportant, whereas in others they may be crucial in establishing a firm in a particular market. Moreover, such lags are generally not rigid but are usually subject to a cost-time trade-off. Despite this fact, we shall assume in this paper that there is an average lag associated with each firm's demand-shifting activities which is fixed technologically and hence cannot be subject to competitive interactions. For analytical simplicity, we shall further assume that this lag is identical for both firms. Our model therefore describes ex-

2. See, for example, Administered Prices, Part I, "Opening PhaseEconomists' Views," Hearings before Subcommittee on Antitrust and Monopoly, Senate Committee on the Judiciary, 85th Congress (Washington, D.C.: U.S. Government Printing Office, 1957); also A. D. Kaplan, Joel B. Dirlam, and Robert F. Lanzillotti, Pricing in Big Business (Washington, D.C.: The Brookings Institution, 1958).

3 . It may seem peculiar to some to have a model which considers newproduct-oriented $R \& D$ and advertising as equivalent types of investment decisions. If one considers them exclusively from the standpoint of investment flows, however, most of the difference which can occur - length of lags, amount of uncertainty, imitatability - are matter of degree rather than kind. One difference is, of course, the possibility of a firm's establishing a proprietary position through patents in $R \& D$, something which is usually impossible in advertising. In the limiting case, patents can completely exclude rivalry and produce a monopoly. However, because antitrust laws will usually prevent this and it is possible for firms to invent around most new product patents anyhow, the relevance of this difference to the analysis is usually not important.

4. In practice, these capital assets may be either concrete in nature (such as patents) or mainly subjective (like consumer goodwill). 
penditures between rivals which are designed to affect demand solely on the basis of increments in the real or perceived quality of their products and not on the basis of acceleration of R\&D to gain competitive lead times and the like. ${ }^{5}$ A more comprehensive model would treat both aspects of competition simultaneously, but this would greatly complicate our analysis of interfirm interactions.

In addition to intra-industry interactions, each firm's demand will naturally be influenced by dynamic developments in the economy as a whole. Population growth, shifts in per capita income, and general technological change can be expected to have selective impacts on all firms in the economic system. In a growing economy, these factors will tend to increase the demand for most products, but they obviously can produce either gains or declines for products in any period due to cyclical fluctuations and allocative adjustments. Since our basic concern is not with such cyclical adjustments but with their general effect over time, all of these factors are aggregated here into a general shift variable which is assumed to change at a constant percentage rate over time. This exogenously determined economy-wide growth rate serves as a benchmark in the analysis against which each firm's growth rate can be measured.

For each firm, therefore, we may write its demand curve in the following mathematical form

$$
Q_{i}(t+n)=F^{i}\left[X_{i}(t), X_{j}(t), Z(t+n)\right] i=1,2 \quad i \neq j
$$

where $Q_{i}(t+n)$ is the demand for the product in physical units of the ith firm at time $t+n ; X_{i}(t)$ and $X_{j}(t)$ are the stocks of demandshifting assets of the $i$ th and $j$ th firms at time $t ; Z(t+n)$ is the economy-wide shift variable at time $t+n ; n$ is the lag in effectiveness in demand-shifting assets.

The assumption of proportional growth for the economy-wide shift variable implies that

$$
Z(t)=Z_{0} e^{g_{0} t}
$$

where $g_{0}$ is economy-wide rate of growth; $Z_{0}$ is a general scale factor.

Now, equation (1) indicates that the stock of a firm's assets as well as its rival's assets will influence its demand with a lag of $n$ time periods, whereas the economy-wide shift factor will influence it without a lag. However, because the economy-wide shift variable is growing at a fixed expotential rate, $g_{0}$, it is clear that for analytical

5. An analysis of duopolistic rivalry which analyzes the timing of new nroduct innovation but not ruality changes is undertaken in F. M. Scherer, "Researeh and Development Resource Allocaticn Under Rivalry," this Journal, I.XXXI (Aug. 1967). His comnarative static analusis focuses on the Cournot solution and considers especially the effects of relative size and market share on the timing of innovational activity. 
convenience we can write each firm's demand curve above as a function of $Z(t)$ in unlagged fashion or

$$
Q_{i}(t+n)=F^{i}\left[X_{i}(t), X_{j}(t), Z(t)\right] \quad i=1,2 \quad i \neq j
$$

by merely redefining the intercept term of the economy-wide shift variable to be $Z_{0}{ }^{\prime}$ so that now we have

$$
Z(t)=Z_{0}{ }^{\prime} e^{g_{0} t} \text { where } Z_{0}{ }^{\prime}=Z_{0} e^{g_{0} n}
$$

In equation (3), the stock of a firm's assets and the economywide shift variable will both affect demand positively (with the postulated lag) subject to the usual diminishing returns assumptions. Mathematically, then, the following conditions apply:

$$
\frac{\partial F^{i}}{\partial X_{i}}>0 \frac{\partial^{2} F^{i}}{\left(\partial X_{i}\right)^{2}}<0
$$

$$
\frac{\partial F^{i}}{\partial Z}>0 \frac{\partial^{2} F^{i}}{(\partial Z)^{2}}<0 \quad i=1,2
$$

as properties which the curves should exhibit.

Correspondingly, each firm's demand should be affected adversely both absolutely and marginally by an increase in a rival's stock so that

$$
\frac{\partial F_{i}}{\partial X_{j}}<0 \frac{\partial^{2} F_{i}}{\partial X_{i} \partial X_{j}}<0 \quad i=1,2 \quad j \neq i
$$

$j \neq i$.

These conditions acknowledge the market-sharing characteristics of the two firms' product lines. Moreover, unless the market is completely static where one firm's loss is exactly the other's gain, we will normally also expect that

$$
\frac{\partial\left(F_{1}+F_{2}\right)}{\partial X_{i}}>0 \quad i=1,2
$$

or demand-shifting activity on the part of either firm also increases total consumption rather than merely redistributing output between the two producers.

In the next section a more exact functional specification will be spelled out for reasons of analytical tractability, but in a manner so as basically to conform to conditions expressed in equations (5) (7).

In order to complete the specification of demand-shifting technology faced by each firm, the stock of each firm's assets at any moment must be related to its investment policies over time. In this regard, each firm will be subject to the usual identity equating the change in stocks at any moment to gross investment minus depreci- 
ation. To complete the model, therefore, the pattern of depreciation must be spelled out. It does not seem unreasonable here to invoke the commonly used capital theoretic assumption of depreciation at a rate proportional to the total stock of assets at any given moment. ${ }^{6}$ Hence net investment in demand-shifting assets, $\stackrel{0}{X}(t)$, will then be related to gross investment, $Y(t)$, by the following relation for each firm:

$$
\stackrel{\circ}{X}_{i}(t)=Y_{i}(t)-\delta_{i} \mathrm{X}_{i}(t) \quad i=1,2
$$

where $\delta_{i}$ is the rate of depreciation in the capital stock of the $i$ th firm.

The formulation of each firm's decision problem may now be quickly completed. If each firm's investment is subjected to a given discount rate, $r_{i}$, the value of discounted profits, $V_{i}$, is equal to ${ }^{7}$

$$
V_{i}=\int_{0}^{\infty} e^{-r} i^{t}\left[R_{i}(t)-C_{i}(t)-U_{i}(t)\right] \quad i=1,2
$$

where $R_{i}(t)$ is total sales at time $t$ for the $i$ th firm and $C_{i}(t)$ is its production cost at time $t ; U_{i}(t)$ is its user cost associated with its demand-shifting capital assets.

The previous assumptions on demand and a fixed product price mean that $R_{i}(t)$ is already fully specified. Regarding production costs, we shall assume a technology embodying constant per unit costs. This simplifies the analysis and is not at variance with several empirical studies of cost functions and related areas. ${ }^{8}$ Finally, in accordance with the general capital theoretic literature, one has a user cost of capital for each firm, $U_{i}$, in this model equal to

$$
U_{i}=\left(r_{i}+\delta_{i}\right) X_{i}(t) \quad i=1,2 .
$$

This change expresses the fact that capital employed here has an opportunity cost which is equal to the interest rate on all capital $r_{i}$ plus the particular rate of depreciation in these assets, $\boldsymbol{\delta}_{i}$.

If we incorporate these assumptions with the ones previously

6. Depreciation here refers to declines in asset value for reasons other than competitive demand-shifting activity undertaken by a rival. The latter is taken account of directly through the interaction term. Rather, this depreciation is identical to what would be experienced even by a monopolist without rivals for reasons such as consumer apathy, ill will, inroads of other industry products, and so on.

7. A constant discount rate either implies that the firm operates in a perfect capital market or applies a target rate to all investment decision which is not influenced by these decisions. If a firm does behave in this manner, it allows us to analyze its investment and sales in separate kinds of markets in an independent manner, provided there are no other direct interdependencies in demand or production of these individual markets. In an age of accelerating conglomeration and multiproduct firms, this ability to segment the analysis would seem to be a most desirable procedure, if it can be justified empirically.

8. For an empirical investigation of this type as well as a survey of the literature, see J. Johnston, Statistical Cost Analysis (New York: McGraw-
Hill Book Co., 1960). 
made, and take account of the lag in capital effectiveness of $n$ periods, the decision-making problem of each firm which wishes to maximize the discounted value of profits, $V_{i}$, is as follows:

Maximize

$$
\begin{aligned}
& V_{i}=\int_{0}^{\infty}\left[e^{-r i^{(t+n)}}\left(p_{i}-c_{i}\right) F^{i}\left(X_{i}, X_{j}, Z\right)\right. \\
& \left.-e^{-i} i^{t}\left(r_{i}+\delta_{i}\right) X_{i}(t)\right] \quad i=1,2 \quad i \neq j
\end{aligned}
$$

where $p_{i}$ and $c_{i}$ are per unit price and production costs and the other symbols are as previously defined, and this is subject to equations (4) and (8) and the inequality conditions given by equations (5)(7).

This is a traditional capital-theoretic problem of the type that has been extensively treated in the literature with the added dimension of oligopolistic interdependence. The fact that the decision problems of each firm are interdependent of course implies that, unless collusion is present, expectational assumptions concerning the behavior of its rival must be made by each firm. In the next section, we turn to a consideration of the complications which this feature introduces in the present dynamic framework and make some further assumptions concerning the firm's demand curve and the nature of its expectations.

\section{Multiplicative Demand Curves and Steady Growth Expectations}

As Nerlove and Arrow show in their analysis of the advertising behavior of a monopolist, very little can be said about the nature of the optimal policy or its comparative dynamics properties when a general functional form or demand is used for this type of model, even when interdependence is not present. For example, in their analysis, the derivation of the comparative dynamic properties of only two parameters - the interest rate, $r$, and the depreciation rate, $\delta$ - were possible with the general functional form. ${ }^{9}$ When particular forms are used, however, the characteristics of the optimal solution become more apparent and comparative dynamic properties of all the parameters are possible.

Using the basic approach of their analysis, we can derive some strong propositions concerning the growth in demand-shifting activity for a monopolist whose demand curve is homogeneous. Specifically, for a monopolist with such a demand curve and also with all the other characteristics of the above analysis (except, of course, in-

9. Nerlove and Arrow, op. cit., pp. 136-37. 
terdependence) ${ }^{1}$ the firm's rate of growth in demand-shifting activity and output will depend directly on the economies to scale properties of its demand curve. In the constant returns to scale case, the firm's optimal policy will involve balanced growth in all firm variables at a steady rate equal to the general economy-wide rate. In the case of nonconstant returns to scale, while balanced or steady growth will not necessarily occur, a firm's rate of growth in demandshifting assets and total output will exceed the general economywide rate under increasing returns and correspondingly will be less than this rate when diminishing returns to scale prevail. ${ }^{2}$ These results for the monopolist are intuitively plausible and are somewhat analogous to those which have been obtained for neoclassical growth models of a more aggregate character. ${ }^{3}$

In the decision-making world of the duopolist, however, the problem assumes the added dimension of rivalry and interdependence. Expectational assumptions must be incorporated into each duopolist's decision problem and these must become mutually consistent for the existence of a stable solution to the problem. In the general functional case, however, the range of possible time paths is hopelessly large and yields a large zone of analytical intractability. Even when each firm is restricted to a homogeneous demand function, there is a large area of uncertainty and instability in the decision-making problem for each firm.

Consider, for example, the case where each firm possesses a homogeneous demand function exhibiting constant returns to scale.

1. This particular reduction of the duopoly model to the monopoly case has some different features from the Nerlove and Arrow model - such as a lag in investment effectiveness - but it is amenable to the same kind of analysis with similar optimality conditions.

2 . These propositions will not be proved rigorously but the basic rationale behind them may be described in simple fashion. In the monopoly case, the demand curve will be a function of two arguments - the firm's stock of assets, $X(t)$, and the economy-wide shift factor, $Z(t)$, so that it may be represented formally as $F(X, Z)$. Now a homogeneous function will have the basic property that its first derivative, $F_{x}$, will increase, remain constant, or decrease as one moves along any ray from the origin, $X / Z$, corresponding to whether increasing, constant, or decreasing returns are exhibited by the function. Now optimal behavior will require the monopolist to obey a certain marginal con. dition on $F_{x}$ over time which will depend on various parameters of the model. However, since these parameters are constants, $F_{x}$ must also be constant over time. But if $F_{x}$ is to remain constant and $Z$ is growing at the steady rate, $g_{0}$, it means that $X$ must also grow at this rate in the constant returns to scale (i.e., it must stay on the same ray). When nonconstant returns to scale hold, the above property and diminishing returns to each factor individually mean that the firm must grow faster in the increasing returns to scale and vice versa in the decreasing returns case. A few additional conditions to insure the existence of such a solution must also be made, but the above properties are the main factors behind the propositions given above.

3. See for example, E. S. Phelps, Golden Rules of Economic Growth (New York: W. W. Norton, 1966). 
So long as each firm expects the other to invest in demand-shifting activity at the general economy-wide rate independent of its own action, then, analogous to the monopoly case discussed above, the optimal behavior of each firm will be to grow in balanced fashion at the general economy-wide rate. ${ }^{4}$ So long as this expectational pattern prevails, there will be a mutually consistent solution. However, if either firm deviates from this pattern, say only to the extent that it expects a rival to accumulate at a steady rate different than the economy-wide rate, the optimal behavior for it will no longer normally involve a steady growth path. Hence one quickly becomes involved in a Pandora's box of possible dynamic solutions and response patterns which can present a very confusing situation to the decision-makers involved.

In the face of this intractability even in the homogeneous case, a more definite functional form would appear necessary together with a consistent set of assumptions regarding firm expectations of rival behavior. On this account, it will therefore be assumed that each firm's demand curve is characterized by a log-linear formulation, or that

$$
\begin{aligned}
& Q_{i}(t+n)=A_{i} X_{i}(t)^{a_{i}} X_{j}(t)^{b_{i}} Z(t)^{k_{\boldsymbol{i}}} \quad i=1,2 \quad i \neq j \\
& \text { with } 0<a_{i}<1,-1<b_{i}<0,0<k_{i}<1 .
\end{aligned}
$$

Multiplicative relations of this type, which imply constant elasticity of demand for all variables, have had widespread use in actual empirical studies of demand. They are also very flexible in exhibiting relevant economic properties. Diminishing returns to each factor are insured by the inequality relations above. The economies to scale properties will depend on sum of the elasticity, and, initially, we shall assume

$$
a_{i}+b_{i}+k_{i}=1 \quad i=1,2
$$

or that constant returns to scale hold for each firm. The total market expansion property given by equation (7) will generally be fulfilled for this function provided $a_{i}>>b_{i}$. This curve therefore has the basic economic properties desired, is not empirically implausible, and, as will be demonstrated, is consistent with the assumptions which will be made about the nature of each firm's expectations.

In regard to this latter question, a reasonable assumption in an expanding economy where all aggregate production and investment variables are assumed to be following an expotential path would seem to be that a rival demand-shifting investment will also follow an expotential path. Over the very long run, one could also con-

4. The proof of this statement is identical to that described in the monopoly case, note 2 , page 223 . 
jecture that the economy-wide growth rate would be a limiting factor on any given firm's investment behavior. Over periods of the normal firm planning horizon, however, one might entertain growth rate expectations above the general rate as reasonable, particularly in a new market situation.

While an assumption of steady growth along some particular expotential path for a rival will certainly miss temporary fluctuations and error for any given period, it would tend to capture the basic pattern of such expenditures over time. In such a framework, each firm must still select the expected level and growth rate of its rival path and predict how its own actions might affect its rival's behavior. This, therefore, is still a complex problem. However, the use of steady growth expectations will be consistent with the above multiplicative demand functions in that the assumption of steady growth along some fixed growth path for a rival will produce a steady growth response. A consistent set of solutions to the above problem is therefore possible.

The assumption of expotential growth at some steady rate may appear as an unnecessarily restrictive assumption and one not in accordance with the observed long-run behavior of firms in real life situations. A more plausible time path might be the familiar Sshaped growth pattern involving rapid growth at first and diminishing efforts as time passes. The effect of any deviations from steady growth over the very long run, however, will have minimum impact on a firm's decision problem because such deviations will be severely discounted. Moreover, over long spans the assumption of steady growth as employed in this model does not contradict patterns of growth like the S-shaped pattern. This is because the steady growth solutions to be analyzed here depend on various parameters which the firm will normally treat as given in any planning context, but which can and will change over longer periods of time. As these parameters change, so will the steady growth which depends on them. Thus, as any given market changes, for example, from increasing to constant to decreasing returns to scale over a long span of time, the model should indicate corresponding changes in each firm's solution in a manner consistent with our economic intuition and empirical observation. ${ }^{5}$ This is a basic criterion which the model must fulfill in the present context, even if it is restricted essentially to steady growth paths.

5. The previously quoted propositions for the monopoly case precisely illustrate this case and lend plausibility to the overall approach employed here. 


\section{Equilibrium Solutions}

The duopolistic decision-making problem as formulated above is a nonzero sum game. The minimax theorem of game theory is not applicable to it. However, various solution concepts are of interest in the present situation. The first question of analytical interest is the existence of an equilibrium pair of steady growth solutions. If we denote a particular steady growth path solution, $X_{i}(t)=B^{\prime}{ }_{i} e^{g} i^{(t)}$, by the shorthand notation $\left(B^{\prime}{ }_{i}, g^{\prime}{ }_{i}\right)$, then we are posing the following question mathematically:

Are there a pair of steady growth paths $\left(B^{\prime}{ }_{1}, g^{\prime}{ }_{1}\right)$ and $\left(B^{\prime}{ }_{2}, g^{\prime}{ }_{2}\right)$ such that

$(14-\mathrm{a})$ overall

$\operatorname{Max} V_{1}\left[\left(B_{1}, g_{1}\right),\left(B_{2}^{\prime}, g_{2}^{\prime}\right)\right]$ is achieved at $\left(B^{\prime}{ }_{1}, g^{\prime}{ }_{1}\right)$

and $\left(B_{1}, g_{1}\right)$

(14-b) overall

Max $V_{2}\left[\left(B_{2}, g_{2}\right),\left(B_{1}^{\prime}, g_{1}^{\prime}\right)\right]$ is achieved at $\left(B_{2}^{\prime}, g_{2}^{\prime}\right)$ $\left(B_{2}, g_{2}\right)$

The equilibrium solution has the desirable property that, once achieved, if either firm decides unilaterally to deviate from this strategy decision, it will result in a loss for that firm, provided the other maintains its equilibrium strategy.

If one were to trace out the locus of dynamic solutions maximizing $V_{1}$ and $V_{2}$ corresponding to all possible steady growth paths on the part of the rival firm, one would have a dynamic equivalent to the familiar Cournot reaction curves of oligopolistic price theory. Correspondingly, an intersection of these curves involving steady growth paths would be an equilibrium point exhibiting the property given by equations (14-a) and (14-b).

We shall therefore proceed directly to an analysis of these curves for the two firms.

Consider firm 1's decision problem, given the expectation of steady growth for firm 2 at a rate independent of its own action:

Maximize

$$
\begin{aligned}
V_{1} & =\int_{0}^{\infty}\left[e^{-r_{1}(t+n)}\left(p_{1}-c_{1}\right) A_{1} X_{1}^{a_{1}}\left(B_{2} e^{g 2^{t}}\right)^{b_{1}}\left(Z_{0}^{\prime} e^{g^{t} t}\right)^{k_{1}}\right. \\
& \left.-e^{-r_{1} t}\left(\delta_{1}+r_{1}\right) X_{1}\right] .
\end{aligned}
$$

The calculus of variations may be used to solve this problem provided a side condition is satisfied. ${ }^{6}$ This condition requires that

6 . See the discussion of this condition and the others which are automatically satisfied in this formulation in Nerlove and Arrow, p. 133. 
(16) $\quad \lim _{t \rightarrow \infty} e^{-r 1^{t}} X_{1}(t)$ exists.

Assuming for the moment that this is the case, we may reduce the Euler equations to the optimality condition

$$
e^{-n r_{1}}\left(p_{1}-c_{1}\right) F x_{1}=\left(r_{1}+\delta_{1}\right) \text {. }
$$

This condition has a simple economic interpretation: namely, at each point in time, the firm should invest in demand-shifting assets up to the point where its net returns equal the opportunity cost of doing so. The net return per unit of $X$ is given on the right-hand side of (17) and is equal to profit per unit of output $\left(p_{1}-c_{1}\right)$, discounted for an effectiveness lag of $n$ periods, $e^{-n r 1}$, times the marginal shift in output associated with an increment in $X_{1}, F x_{1}$. The opportunity cost is the sum of the interest rate, $r_{1}$, plus the depreciation rate, $\delta_{1}$.

Application of this condition to the problem will lead to an optimal growth path for firm 1 involving steady growth or a solution of the form

$$
X_{1}(t)=B_{1} e^{g_{1} t}
$$

where $B_{1}$ and $g_{1}$ are related to the parameters of the model in a manner to be discussed below. The side condition given, for example, by equation (16), with this solution reduces to the simple equality (16-a) $g_{1}<r_{1}$

which has the simple economic interpretation that the firm growth rate must be less than the interest rate, or the above integral approaches infinity and there is no basis for choosing among any policies.

In the optimal solution, the parameters $B_{1}$ and $g_{1}$ will be related to other factors in the following fashion:

$$
\begin{aligned}
(19-\mathrm{a}) \quad B_{1} & =\left[A_{1} \frac{\left(p_{1}-c_{1}\right) e^{-n r_{1}}}{\left(r_{1}+\delta_{1}\right)} a_{1}\left(Z_{0}^{\prime}\right)^{k_{1}}\right] \frac{1}{1-a_{1}}\left[B_{2}\right]^{\frac{b_{1}}{1-a_{1}}} \\
& =K_{1}^{\frac{1}{1-a_{1}}} B_{2} \frac{b_{1}}{1-a_{1}} \\
\text { (19-b) } g_{1} & =\frac{k_{1} g_{0}}{1-a_{1}}+\frac{b_{1}}{1-a_{1}} g_{2} .
\end{aligned}
$$

Using the property of notational symmetry, we can obtain a corresponding solution for firm 2 with subscripts 1 changed to 2 and vice versa, so that

$$
\text { (20-a) } \quad B_{2}=K_{2}^{\frac{1}{1-a_{2}}} B_{1} \frac{b_{2}}{1-a_{2}}
$$


(20-b) $g_{2}=\frac{k_{2} g_{0}}{1-a_{2}}+\frac{b_{2}}{1-a_{2}} g_{1}$.

These reaction curves have some interesting properties. First of all, we note that the pair of reaction curves associated with the levels of the growth path are not dependent on the rival's growth rate while those dealing with the growth rates are independent of levels. Therefore, the two sets of reaction curves may be analyzed independently. Furthermore, equations $(19-b)$ and $(20-b)$ indicate that along the growth rate reaction curves, the rate of growth in output for each firm, $a_{i} g_{i}+b_{i} g_{j}+k_{i} g_{o}$, will be equal to that in demand-shifting assets, $g_{i}$. These reaction curves are therefore the loci of balanced growth paths for each firm. Hence, at points above and below these curves, the firm will experience unbalanced growth with $g_{i}$ greater than the corresponding output growth at points above and less than it when below.

The growth rate reaction curves are shown in Figure I. They have negative slopes, and because of the constant returns to scale property on the elasticity coefficients, must intersect at the economywide rate, so that

$$
g_{1}^{\prime}=g_{2}^{\prime}=g_{0} \text {. }
$$

This is the only mutually consistent pair of balanced growth paths

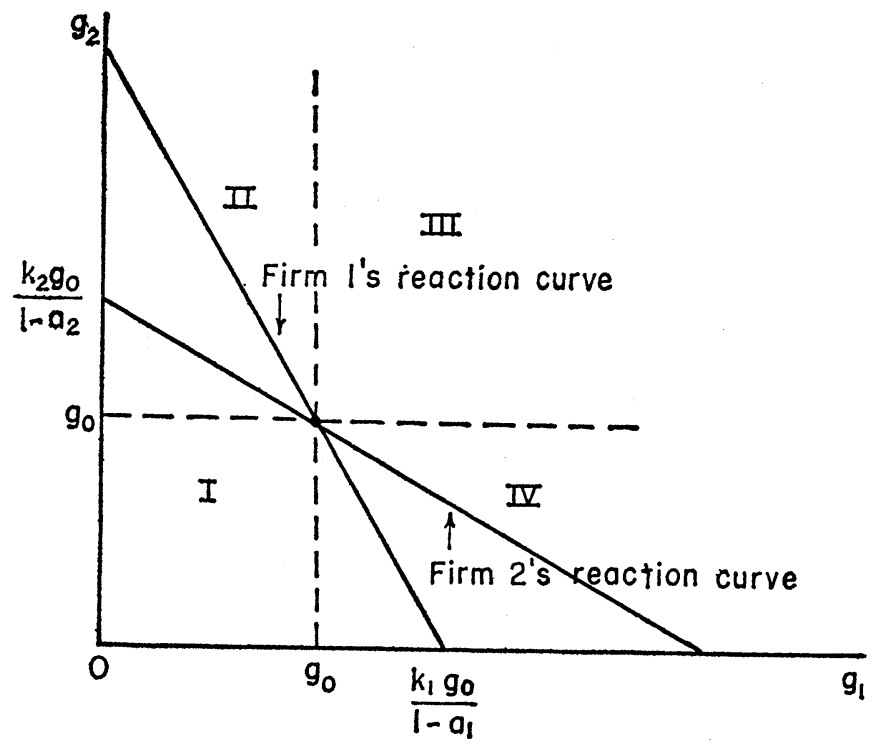

Figure I

Growth Rate Reaction Curves under Constant Returns To Scale 
possible and the only pair of growth rates which can be in equilibrium. An analysis of the effect of changes in the scale properties on this solution, while straightforward, will be deferred to a later section where nonsymmetrical scale properties for the two firms will be considered.

The reaction curves associated with the levels of the growth paths will be nonlinear and will depend on the other parameters in addition to the elasticity coefficients. The solution of these equations yields the equilibrium levels for $B^{\prime}{ }_{1}$ given

$$
\begin{aligned}
B_{1}^{\prime}=\left[K_{1}\right] \frac{1-a_{2}}{\frac{b_{1}}{\left(1-a_{1}\right)\left(1-a_{2}\right)-b_{1} b_{2}}} \\
\cdot\left[K_{2}\right] \frac{b_{1}}{\left(1-a_{1}\right)\left(1-a_{2}\right)-b_{1} b_{2}}
\end{aligned}
$$

and an identical expression for $B_{2}^{\prime}$ with subscripts reversed. These expressions for $B^{\prime}{ }_{1}$ and $B^{\prime}{ }_{2}$ will have at least one pair of positive solutions. ${ }^{7}$ Therefore, an equilibrium solution for this model exists which is characterized by a steady rate of growth in all variables at the economy-wide rate.

The comparative statics relations of $B^{\prime}{ }_{1}$ and $B^{\prime}{ }_{2}$ to most of the model's parameters can be directly obtained and are in accordance with one's intuition. Consider the expression for $B^{\prime}{ }_{1}$ given by equation (22). The elasticity coefficients are such to yield a positive exponent on $K_{1}$ and a negative one for $K_{2}$. This in turn means that $B^{\prime}{ }_{1}$ will be positively related to increases, ceteris paribus, in firm 1's scale coefficients, $A_{1}$ and $Z_{0}$; and conversely it will be negatively related to its cost per unit, $c_{1}$, discount rate, $r_{1}$, and depreciation coefficient $\delta_{1}$. Since the exponent on $K_{2}$ is negative, it will be related to these parameters of firm 2 in opposite fashion. However, because the length of lag, $n$, is common to both firms, any change in it on technological grounds will have a mixed effect and the total effect cannot be stated unambiguously.

The effects of changes in the elasticity coefficients on the equilibrium levels are also mixed and a composite of opposing forces. This is because there is an identity relation between these coefficients as a result of the constant returns to scale assumption and changes strictly ceteris paribus cannot occur in any of them as long as this constraint holds. The individual components of these reactions can

7. The possibility of more than one equilibrium pair of growth level paths arises from the existence of multiple roots to both expotential terms in equation (22). 
be derived, however, and are basically in accord with intuitive expectations.

These properties of the Cournot solution, taken together, indicate that it has a "live and let live character" where each firm grows in a balanced fashion with itself, its rival, and the general economywide rate. Any asymmetries which occur are reflected in the levels of the growth paths and not in the growth rates of firms. Moreover, the countervailing power which each firm possesses with regard to its rival is recognized by the basic nature of such a solution, its stability against unilateral actions.

One could summon a Cournot dynamic response pattern to justify the historical emergence of such a solution. For such a dynamic pattern to be stable, however, the curves must intersect in the fashion of Figure I - the reaction curve of firm 1 above that of firm 2 in quadrant II and vice versa in quadrant IV. The plausibility of such an intersection aside, the Cournot behavioral response pattern inherently has some well-known drawbacks. It essentially involves a "naive" expectational pattern in which a series of local optimums on the part of a firm may lead to a global result which is dramatically inferior to the starting point. Nevertheless, under situations of high uncertainty, the Cournot reaction pattern may be relevant for want of a better alternative. In another section, we will show that a frequent rule of thumb employed by firms in such uncertain situations, pegging investment to sales levels, leads to a solution having the same growth rate properties as the Cournot equilibrium point given here, and this would seemingly enhance its plausibility as a solution concept.

\section{Nonconstant Returns to Scale}

Up to now, all of the analysis has assumed that the demand curves of each firm are symmetric with respect to a very important characteristic - namely, constant returns to scale. However, the presence of nonconstant returns to scale in one or both demand functions can easily be incorporated into the above analysis.

With regard to the Cournot solution described in Section III, changes in the scale properties will cause a shift in the growth rate reaction curves given in Figure I and thus change the properties of that solution. ${ }^{8}$ For example in terms of Figure I, the presence of

8. The rate of growth in demand-shifting assets for firm 1 and firm 2 must not exceed their corresponding discount rates, $r_{2}$ and $r_{2}$ respectively, or the integral equation on profits will not be bounded. These discount rates therefore serve as the outer limits on the growth rates in this kind of analysis. 
increasing returns will cause a firm's reaction curve to be above the previous Cournot equilibrium point $\left(g_{0}, g_{0}\right)$ while the reverse will hold true for diminishing returns. ${ }^{9}$ Thus if firm 1 exhibits increasing returns to scale while firm 2 has constant returns, the new Cournot equilibrium must be in region IV of the diagram. This means firm 1's growth rate will be greater than $g_{0}$ and firm 2's less than $g_{0}$.

Using the above relations, we may chart the effect on the Cournot equilibrium arising from various combinations of assumptions regarding the scale properties of the two firms' demand function. Table I presents this information.

\section{TABLE I}

The Cournot Equilibrium Solution for Various Assumptions on the Scale Properties of the Demand Functions for the Two Firms

\begin{tabular}{|c|c|c|c|}
\hline & $\begin{array}{l}\text { Increasing } \\
\text { returns }\end{array}$ & $\begin{array}{c}\text { Firm } 2 \\
\text { Constant }\end{array}$ & Decreasing \\
\hline $\begin{array}{l}\text { Increasing } \\
\text { returns to } \\
\text { scale }\end{array}$ & $\begin{array}{l}\text { indeterminate } \\
\text { both } g_{1} \text { and } g_{2} \\
\text { cannot be less } \\
\text { than } g_{0}\end{array}$ & $g_{1}^{\prime}>g_{0}>g_{2}^{\prime}$ & $g_{1}^{\prime}>g_{0}>g^{\prime}$ \\
\hline
\end{tabular}

Firm 1 Constant $\quad g_{1}^{\prime}<g_{0}<g^{\prime}{ }_{2} \quad g_{1}^{\prime}=g_{0}=g^{\prime}{ }_{2} \quad g_{1}^{\prime}>g_{0}>g^{\prime}$

\begin{tabular}{ccc}
\cline { 2 - 2 } & & $\begin{array}{c}\text { indeterminate } \\
\text { both } g_{1} \text { and } g_{2} \\
\text { cannot be greater } \\
\text { than } g_{0}\end{array}$
\end{tabular}

Table I shows that, if a firm operates with a demand function which has qualitatively inferior scale properties to its rival, this condition will be sufficient to push its equilibrium growth rate below the general economy-wide rate and vice versa. Moreover, when both firms exhibit increasing or decreasing returns to scale, various types of equilibrium are possible with only a single region of Figure I ruled out in each case. These results therefore illustrate that it is the scale properties of a firm relative to its rivals which are crucial in the present duopolistic version of the model. Therefore, as one

9. One may verify this by directly substituting rival growth at $g_{0}$ into each firm's reaction curve and noting that the resulting growth rate will be more or less depending on whether the elasticity coefficients are greater than or less than 1. 
might expect, significant differences in the technology of demand shifting can be the basis for one firm's assuming a dominant position in a particular market.

\section{Rule-of-Thumb Decision Making and Steady Growth Solutions}

A prominent rule of thumb for allocating expenditures to both $\mathrm{R} \& \mathrm{D}$ and advertising that frequently has been mentioned in the business trade literature is the allocation of a fixed percentage of sales to these activities. ${ }^{1}$ Given the apparent widespread use of this kind of decision rule, it is worth restructuring the present analysis to investigate what happens when it is incorporated as one of the initial assumptions of the model. Specifically, it is assumed that each firm in the duopoly model of the previous two sections devotes a constant but not necessarily equal percentage of its sales to demand-shifting activity. The other assumptions are retained except for that of optimality calculations and the behavioral assumptions regarding steady growth on the part of the rival firm, which are replaced by this decision rule.

In our new model we have the new behavioral relations

$$
Y_{i}(t)=s_{i} p_{i} Q_{i}(t) \text { where } 0<s_{i}<1 \text { for } i=1,2,
$$

together with the previous multiplicative demand functions for $Q_{1}$ and $Q_{2}$ (equation (12) ), and the relations on the depreciation of demand-shifting assets for each firm (equation (8)) and growth of the economy-wide shift parameter at a constant percentage rate (equation (4)).

This group of equations may be quickly reduced by substitution to the following simultaneous pair of mixed differential difference equations

$$
\begin{aligned}
& \frac{Y_{i}(t)}{s_{i}}=\frac{\stackrel{o}{X_{i}}(t)+\delta_{i} X_{i}(t)}{s_{i}} \\
&=p_{i} A_{i}\left[X_{i}(t-n)\right]^{a_{i}}\left[X_{j}(t-n)\right]^{b_{i}}[Z(t-n)]^{k_{i}} \\
& i=1,2 \quad i \neq j .
\end{aligned}
$$

1. See "Decision-Making on Research and Development in the Business Firm," National Science Reviews of Data on Research and Development (NSF 64-6, Feb. 1964). See also the discussion of this question in H. Grabowski, The Determinants and Effects of Industrial Research and Development, Research Memorandum No. 82, Princeton University, Econometric Research Program (Sept. 1966), pp. 35-75. With regard to the advertising decision, see N. H. Borden, The Economic Effects of Advertising (Chicago: Richard D. Irwin, Inc., 1952). 
An equilibrium solution to this pair of equations is given by ${ }^{2}$

$$
X_{1}(t)=W_{1} e^{g_{1} t}, X_{2}(t)=W_{2} e^{g 2^{t}}
$$

where $\left(g_{1}, g_{2}\right)$ is given by the solution to the linear equations:

$$
g_{i}=\frac{k_{i} g_{0}}{1-a_{i}}+\frac{b_{i}}{1-a_{i}} g_{j} \quad i=1,2 \quad i \neq j
$$

and $W_{1}$ and $W_{2}$ are a function of $s_{1}$ and $s_{2}$ and the other parameters of the model in the following manner:

$$
\begin{aligned}
& W_{i}=\left(s_{i} K_{i}^{\prime}\right) \quad \frac{1-a_{j}}{\frac{b_{i}}{\left(1-a_{i}\right)\left(1-a_{j}\right)-b_{i} b_{j}}} \\
& \quad \cdot\left(s_{j} K_{j}^{\prime}\right) \quad \frac{\left.b_{j}\right)\left(1-a_{j}\right)-b_{i} b_{j}}{\left(1-a_{i}\right)} \\
& i=1,2 \quad i \neq j .
\end{aligned}
$$

The terms $K_{i}^{\prime}$ and $K_{j}^{\prime}$ are related to the model's parameters in identical fashion to $K_{i}$ and $K_{j}$ in the Cournot equilibrium solution except for the fact that $g_{i}$ replaces $r_{i}$ wherever it appears.

The above solutions indicate that the rule-of-thumb decision approach, provided it is dynamically stable, will lead to a solution of balanced growth at the Cournot equilibrium pair of growth rates, but at growth path levels which are not necessarily equal to Cournot equilibrium levels, but instead depend on the particular allocations, $s_{i}$ and $s_{2}$, undertaken by the two firms.

The fixed percentage allocations of investment in demand-shifting assets to sales in this situation necessarily require firms to pursue balanced growth paths in equilibrium, and the only pair of growth rates which simultaneously solve both difference differential equations are those of the Cournot equilibrium solution previously derived. On the other hand, there is no requirement in the present model, as in the Cournot solution, that each firm pursue that level of growth path which maximizes its net discounted profit for any given level of growth path on the part of its rival. Of course, one could formulate such a requirement in terms of the $s_{i}$ allocations and the model would formally reduce to the Cournot equilibrium case with a mutually consistent solution occurring at corresponding levels for $s_{i}$ and $s_{2}$. The use of these rules of thumb would seem to be in a quite different spirit. The firms, in a highly uncertain environment, are unable to make a calculation on optimal behavior, even if a rival's rule-of-thumb behavior were constant, and elect a certain per-

2. One may verify the validity of this solution by direct substitution. However, this is only an equilibrium solution and a full solution will necessarily depend on transient terms and initial conditions. We implicitly assume convergence in the analysis undertaken here. 
centage on the basis of a variety of influences - ability to pay, general industry norms, and so on.

It is interesting to note that one empirical investigation of the $R \& D$ decision concluded statistically in favor of a ratchet effect pattern on which the R\&D-to-sales ratio tended to be stable for several budget periods, then experienced a jump over a short period of time, followed by another lengthy period of stability. ${ }^{3}$

Whether this pattern is widespread or not, the above rule-ofthumb model suggests why the firms would be susceptible to this type of behavior. Since the two firms' levels will not be in equilibrium except by accident, the possibility of gains by unilateral action on the part of either firm is not foreclosed. If one firm initiates an increase in its ratio, the other must make a choice whether it is in its best interest to follow. If it starts to observe significant gains in its market by the other firm, the profitability of which will be difficult to discern, the natural tendency will be to increase its ratio in retaliation. If the net result of these joint increases benefits neither firm, which is likely, the learning process should promote stability for a period of time until memories grow short or a new entrant into the market initiates another round of increases.

From a more general prospectus, this rule-of-thumb decisionmaking model has the advantage that it does not require the formulation of any expectations concerning the pattern of the rival's growth path. It is thus more amenable to direct generalization than the Cournot solution. For example, any homogeneous function of degree one with this model will yield an equilibrium solution with both firms at the economy-wide rate, $g_{0}$. Steady growth of one's rival at this rate is an outcome of the analysis in this situation, rather than a necessary expectational assumption as in the Cournot case (Section II). Therefore this sample rule of thumb can be a viable mechanism for avoiding the knife-edge type of instability associated with incorrect expectations that often plagues a more general Cournot type analysis, while yielding a similar equilibrium solution as far as firm growth rates are concerned.

\section{Summary and Conclusions}

In this paper, equilibrium steady growth paths were analyzed for a model of demand-shifting activity under oligopolistic conditions. It was shown that the level of each firm's equilibrium growth path is sensitive to many parameters denoting the demand and cost

3. National Science Reviews of Data on Research and Development, p. 5. 
situations confronting the two rival firms. However, each firm's equilibrium growth rate depends only on the general economy-wide rate and the scale properties of its demand curve relative to that of its rival.

It was further demonstrated that steady growth solutions with these comparative dynamic properties may be obtained formally using a capital theoretic approach and a Cournot behavioral response pattern or, alternatively, from a rule-of-thumb decisionmaking procedure suggested in the business survey literature. Accordingly, this type of model may prove useful in empirical studies of demand-shifting allocations under conditions of high uncertainty, where such rule of thumb procedures are apt to be especially prevalent.

YALE UNIVERSITY 